\title{
Autonomic dysfunction and primary antiphospholipid syndrome: a frequent and frightening correlation?
}

This article was published in the following Dove Press journal:

International Journal of General Medicine

12 April 2012

Number of times this article has been viewed

\author{
Franca Bilora \\ Michela Biasiolo \\ Alice Zancan \\ Ezio Zanon \\ Francesco Veronese \\ Francesca Manca \\ Maria Teresa Sartori \\ Second Internal Medicine Clinic, \\ Department of Cardiovascular and \\ Thoracic Sciences, University of \\ Padua, Padova, Italy
}

Introduction: the correlation between primary antiphospholipid syndrome (APS) and cardiovascular events is well known, but the correlation between APS and sudden death is not clear; it probably correlates with sympathetic alterations of the autonomic system.

Aim: To compare the autonomic nervous system (ANS) in a group of subjects suffering from APS against that of a control group with no cardiovascular risk factors, matched for age, sex, and body mass index.

Subjects and methods: An equal number $(n=31)$ of subjects with APS, and healthy controls, underwent autonomic evaluation: tilt test, deep breath, Valsalva maneuver, hand grip, lyingto-standing, Stroop, and sweat tests.

Results: Cases in the APS group were positive for the tilt test, relating to changes in respiratory rate intervals, by comparison with controls. Results of other tests were also altered significantly in APS cases, by comparison with controls. (The sweat and Stroop tests were only performed in 14 cases). Autonomic disease did not correlate with age, sex, history of disease, arterial or venous thrombosis, or antibody positivity; only their coagulation parameters correlated with autonomic dysfunction.

Conclusion: Autonomic dysfunction in APS seems to correlate with coagulation parameters. APS patients should receive autonomic evaluation, to minimize the risks of fatal arrhythmias and sudden death.

Keywords: autonomic dysfunction, primary antiphospholipid syndrome

\section{Introduction}

Antiphospholipid syndrome (APS) is characterized by thrombosis, miscarriage, or thrombocythemia associated with positivity for lupus anticoagulant (LAC) or anticardiolipin antibody tests. ${ }^{1,2}$ APS was initially described in patients with autoimmune disease, especially systemic lupus erythematosus (SLE), secondary to this disease. ${ }^{3}$ The syndrome has also been described in subjects with no autoimmune disorder, where it is known as primary APS. ${ }^{4}$

Patients with rheumatic disease, even subclinically, often show cardiovascular and neural symptoms. The autonomic system is certainly affected, but reports are conflicting, for various reasons. Autonomic symptoms vary, ranging from gastrointestinal, to cardiovascular, to neural. Autonomic tests are not routinely performed. It is difficult to differentiate secondary cardiovascular effects, due to therapy, from the effects of the disease.

Research on autonomic dysfunction (AD) in autoimmune disease has identified alterations, with variability in the range of $24 \%-100 \%$, depending on the method used. ${ }^{5}$
Clinica Medica II, Università di Padova,

Via Giustiniani 2, 35I 28 Padova, Italy

Tel +390498218272

Fax +390498212661

Email franca.bilora@sanita.padova.it 
Cardiovascular autonomic dysfunction is most common in autoimmune diseases. ${ }^{6}$ The role of AD is debated. Attention has focused mainly on an "overreactivity of the sympathetic nervous system" point of view. This proposes that a central alteration may be involved. The role of the peripheral nervous system is uncertain. ${ }^{6,7}$

Our case-control study aimed to elucidate these contrasting findings, and to clarify the correlation between APS and sudden death.

\section{Subjects and methods}

We examined 107 subjects with primary APS, diagnosed on the basis of the classic clinical and laboratory criteria (ie, a positive history of deep venous or arterial thrombosis or miscarriage, and antiphospholipid antibody positivity in two blood samples, obtained 2 months apart). All individuals were outpatients and were recruited during a period of 1 year (September 2008 to September 2009).

For each case, we recorded the patient's clinical history, physical examination, electrocardiographic derivations (12-lead electrocardiogram [ECG]), and blood test findings, to assess cardiovascular risk factors (ie, smoking habits, hypertension, diabetes mellitus, hypercholesterolemia, and obesity) (Table 1), to check against exclusion criteria, and to identify any diseases correlated with atherosclerosis (ie, acute myocardial infarction, angina pectoris, transient ischemic attack, stroke, carotid endarterectomy, arterial vascular disease, or aortic aneurysm). We excluded subjects with autoimmune, neoplastic, thyroid, or hemorrhagic diseases, and those taking steroids or contraceptive pills.

Of the 107 cases observed, we excluded 76 because they had risk factors for atherosclerosis or previous clinical manifestations of atherosclerosis. The 31 remaining cases were paired with 31 healthy subjects, with no common risk factors for atherosclerosis, who were recruited at our clinic during the same observation period.

\section{Antiphospholipid antibody assay}

Antiphospholipid antibodies were measured in a 1:100 plasma dilution, using the Asserachrom ${ }^{\circledR}$ APA system (Diagnostica

Table I Atherosclerotic risk factors

\begin{tabular}{ll}
\hline Risk factor & \\
\hline Smoking habits & $>5$ cigarettes/day \\
Hypertension & Blood pressure $>140 / 90 \mathrm{mmHg}$ or therapy \\
Diabetes & Fasting glycemia $>6.1 \mathrm{mMol} / \mathrm{L}$ or therapy \\
Hypercholesterolemia & Cholesterol $>5.2 \mathrm{mMol} / \mathrm{L}$ or therapy \\
Obesity & BMI $>30$
\end{tabular}

Abbreviation: BMI, body mass index.
Stago, Paris, France). The dilutions used for calibration were double-tested. Results were plotted on log-log graph paper, and the approximate plasma potential (UPL) levels were read from the calibration curve. Levels less than 10 UPL were considered negative. Levels between 11 and 15 were considered mildly positive; levels between 15 and 40 were considered moderately positive; and levels greater than 40 were considered highly positive. The 10 UPL cut-off was approximately two standard deviations (SDs) higher than the mean level of 50 controls. Each test was duplicated.

The guidelines of the International Society on Thrombosis and Hemostasis Subcommittee for Standardization were followed for LAC detection, as reported elsewhere. ${ }^{8,9}$

\section{Tilting and autonomic tests}

Subjects underwent cardiovascular autonomic nerve function tests, ${ }^{10}$ performed in the following order: (1) deep breath, (2) Valsalva test, (3) isometric hand grip, (4) lyingto-standing. In the deep breath test, a test for vagal heart rate control, ${ }^{11}$ the duration of the expiratory and inspiratory breaths was 5 seconds each, for a total of 40 seconds (four breathing cycles). The ratio of the longest to the shortest respiratory rate (RR) intervals was measured from the ECG for each breathing cycle. The mean of all four ratios was taken as the expiratory/inspiratory (E/I) ratio. Respiratory rate was measured using a chronograph.

For the Valsalva test, which measures both parasympathetic and sympathetic function, subjects blew into a manometer maintaining an intrathoracic pressure of $40 \mathrm{mmHg}$ for 15 seconds. The Valsalva ratio, of the shortest RR interval during the expiratory effort to the longest $\mathrm{RR}$ interval during the 20 seconds subsequent to strain, was calculated. The RR interval was measured from the ECG printout. Blood pressure was assessed using an automated sphygmomanometer (TECNOMED, Udine, Italy).

In the isometric hand grip test, the subjects squeezed a dynamometer (TECNOMED) in their dominant hand for 3 minutes, using a force that corresponded to $30 \%$ of

Table 2 Characteristics of the population examined

\begin{tabular}{lll}
\hline & Cases & Controls \\
\hline Sex & I3 male, I8 female & I3 male, I8 female \\
Age & $47.4 \pm 2$ I years & $48.9 \pm 25$ years \\
BMI & $23.6 \pm 9.4$ & $24.3 \pm 10.7$ \\
Heart rate & $76.4 \pm 13.4$ & $69.8 \pm 18.1$ \\
Hypertension & No & No \\
Smoking & No & No \\
Diabetes & No & No \\
\hline
\end{tabular}

Abbreviation: BMI, body mass index. 
Table 3 Autonomic tests in cases and controls

\begin{tabular}{llcl}
\hline Autonomic test & Cases & Controls & $\boldsymbol{P}$ \\
\hline Tilt (RR ratio) & $1.10 \pm 0.09$ & $1.14 \pm 0.1 \mathrm{I}$ & $<0.05$ \\
Hand grip (mmHg) & $5.75 \pm 5.14$ & $10.55 \pm 12.73$ & $<0.05$ \\
Deep breath (E/I ratio) & $1.15 \pm 0.11$ & $1.40 \pm 0.15$ & $<0.05$ \\
Valsalva (valsalva ratio) & $1.33 \pm 0.19$ & $1.74 \pm 0.42$ & $<0.05$ \\
Lying-to-standing (mmHg) & $0.55 \pm 10.31$ & $-9.81 \pm 4.95$ & $<0.05$ \\
\hline
\end{tabular}

Abbreviations: RR, respiratory rate; E/l, expiratory/inspiratory.

their maximal squeezing force. Heart rate and blood pressure were measured at rest, before, and after gripping the dynamometer.

For the lying-to-standing test, subjects stood up suddenly, after lying quietly in a supine position for 5 minutes. Heart rate and blood pressure were measured at rest, then at 1, 3, 5 , and 7 minutes after standing up.

In the tilt test, the subject lay supine on an electric tilting table (TECNOMED). A restraining strap across the upper abdomen secured the subject to the table during the test, applying a negligible pressure to the surface of the body. Blood pressure and ECG recordings were obtained continuously throughout the test, which lasted 30 minutes. The test was considered to be positive only in the presence of symptoms fully reproducing a patient's original pre-syncopal or syncopal symptoms, accompanied by arterial hypotension, bradycardia, or both. ${ }^{12,13}$

For the Stroop test, subjects were asked to read the names of seven colors, written on sheets of paper, as fast as they could, while lying down. The names of the colors were written in colors different than those they named (eg, the word "green" was written in yellow). This test represents a mental stressor. In normal subjects, blood pressure and heart rate should rise by the end of the test. ${ }^{14}$

The quantitative sudomotor autonomic reflex test measures the activity of small nerve fibers connected to sweat glands. The foot, leg, and forearm are typical test sites. ${ }^{15} \mathrm{~A}$ capsule was placed over the skin on the test site. A technician then stimulated a nearby sweat gland, by delivering a chemical substance through the skin, using a low-

Table 4 Correlation between sex and autonomic tests

\begin{tabular}{llll}
\hline Autonomic test & Males & Females & $\boldsymbol{P}$ \\
\hline Tilt (RR ratio) & $1.09 \pm 0.13$ & $1.10 \pm 0.03$ & $\mathrm{~ns}$ \\
Hand grip (mmHg) & $4.85 \pm 5.79$ & $6.39 \pm 4.69$ & $\mathrm{~ns}$ \\
Deep breath (E/l ratio) & $1.10 \pm 0.1 \mathrm{I}$ & $1.19 \pm 0.09$ & $\mathrm{~ns}$ \\
Valsalva (valsalva ratio) & $1.27 \pm 0.25$ & $1.37 \pm 0.13$ & $\mathrm{~ns}$ \\
Lying-to-standing (mmHg) & $4.08 \pm 13.93$ & $-2.0 \pm 5.86$ & $\mathrm{~ns}$ \\
\hline
\end{tabular}

Abbreviations: RR, respiratory rate; E/l, expiratory/inspiratory; ns, not significant.
Table 5 Correlation between age and autonomic tests

\begin{tabular}{lcll}
\hline Autonomic test & Age $<\mathbf{5 0}$ years & Age $>\mathbf{5 0}$ years & $\boldsymbol{P}$ \\
\hline Tilt (RR ratio) & $\mathrm{I} .1 \mathrm{I} \pm 0.03$ & $1.09 \pm 0.12$ & $\mathrm{~ns}$ \\
Hand grip $(\mathrm{mmHg})$ & $7.01 \pm 5.67$ & $4.40 \pm 4.29$ & $\mathrm{~ns}$ \\
Deep breath (E/I ratio) & $\mathrm{I} .19 \pm 0.10$ & $1.18 \pm 0.11$ & $\mathrm{~ns}$ \\
Valsalva (valsalva ratio) & $1.38 \pm 0.13$ & $1.27 \pm 0.24$ & $\mathrm{~ns}$ \\
Lying-to-standing (mmHg) & $-1.63 \pm 6.76$ & $2.87 \pm 12.96$ & $\mathrm{~ns}$ \\
\hline
\end{tabular}

Abbreviations: RR, respiratory rate; E/l, expiratory/inspiratory; ns, not significant.

Table 6 Correlation between age at first manifestation and autonomic tests

\begin{tabular}{lccc}
\hline Autonomic test & $\begin{array}{l}\text { Age at first } \\
\text { manifestation } \\
<\mathbf{3 0} \text { years }\end{array}$ & $\begin{array}{l}\text { Age at first } \\
\text { manifestation } \\
>\mathbf{3 0} \text { years }\end{array}$ & $\boldsymbol{P}$ \\
\hline Tilt (RR ratio) & $\mathrm{I} .10 \pm 0.02$ & $1.1 \mathrm{I} \pm 0.03$ & $\mathrm{~ns}$ \\
Hand grip (mmHg) & $4.34 \pm 3.03$ & $5.00 \pm 5.37$ & $\mathrm{~ns}$ \\
Deep breath (E/l ratio) & $1.23 \pm 0.07$ & $1.21 \pm 0.09$ & $\mathrm{~ns}$ \\
Valsalva (valsalva ratio) & $1.40 \pm 0.12$ & $1.34 \pm 0.11$ & $\mathrm{~ns}$ \\
Lying-to-standing (mmHg) & $-2.22 \pm 6.98$ & $-1.13 \pm 6.03$ & $\mathrm{~ns}$ \\
\hline
\end{tabular}

Abbreviations: RR, respiratory rate; E/I, expiratory/inspiratory; ns, not significant.

Table 7 Correlation between arterial or venous thrombosis at first manifestation and autonomic tests

\begin{tabular}{lccc}
\hline Autonomic test & Arterial events & Venous events & $\boldsymbol{P}$ \\
\hline Tilt (RR ratio) & $\mathrm{I} .1 \mathrm{I} \pm 0.03$ & $1.10 \pm 0.02$ & $\mathrm{~ns}$ \\
Hand grip (mmHg) & $5.47 \pm 4.44$ & $3.02 \pm 1.98$ & $\mathrm{~ns}$ \\
Deep breath (E/I ratio) & $1.18 \pm 0.10$ & $1.20 \pm 0.10$ & $\mathrm{~ns}$ \\
Valsalva (valsalva ratio) & $1.37 \pm 0.11$ & $1.35 \pm 0.10$ & $\mathrm{~ns}$ \\
Lying-to-standing (mmH) & $-1.33 \pm 6.16$ & $-1.40 \pm 6.62$ & $\mathrm{~ns}$ \\
\hline
\end{tabular}

Abbreviations: RR, respiratory rate; E/l, expiratory/inspiratory; ns, not significant.

Table 8 Correlation between history of disease and autonomic tests

\begin{tabular}{lccc}
\hline Autonomic test & $\begin{array}{l}\text { History } \\
<\mathbf{I 5} \text { years }\end{array}$ & $\begin{array}{l}\text { History } \\
>\mathbf{I 5} \text { years }\end{array}$ & $\boldsymbol{P}$ \\
\hline Tilt (RR ratio) & $1.11 \pm 0.04$ & $1.10 \pm 0.02$ & $\mathrm{~ns}$ \\
Hand grip (mmHg) & $5.42 \pm 5.08$ & $4.68 \pm 3.26$ & $\mathrm{~ns}$ \\
Deep breath (E/l ratio) & $1.21 \pm 0.08$ & $1.16 \pm 0.10$ & $\mathrm{~ns}$ \\
Valsalva (valsalva ratio) & $1.38 \pm 0.15$ & $1.36 \pm 0.09$ & $\mathrm{~ns}$ \\
Lying-to-standing $(\mathrm{mmHg})$ & $-1.58 \pm 7.41$ & $-0.89 \pm 6.13$ & $\mathrm{~ns}$ \\
\hline
\end{tabular}

Abbreviations: RR, respiratory rate; E/l, expiratory/inspiratory; ns, not significant.

Table 9 Correlation between antibody positivity and autonomic (APA) tests

\begin{tabular}{lrrr}
\hline Autonomic test & APA $<\mathbf{2 0}$ & APA $>\mathbf{2 0}$ & $\boldsymbol{P}$ \\
\hline Tilt (RR ratio) & $\mathrm{I} .1 \mathrm{I} \pm 0.03$ & $\mathrm{I} .10 \pm 0.02$ & $\mathrm{~ns}$ \\
Hand grip (mmHg) & $5.42 \pm 4.93$ & $4.68 \pm 3.4 \mathrm{I}$ & $\mathrm{ns}$ \\
Deep breath (E/I ratio) & $\mathrm{I} .21 \pm 0.1 \mathrm{I}$ & $\mathrm{I} .16 \pm 0.09$ & $\mathrm{~ns}$ \\
Valsalva (valsalva ratio) & $\mathrm{I} .38 \pm 0.1 \mathrm{I}$ & $\mathrm{I} .36 \pm 0.07$ & $\mathrm{~ns}$ \\
Lying-to-standing (mmHg) & $-\mathrm{I} .58 \pm 6.56$ & $-0.89 \pm 5.86$ & $\mathrm{~ns}$ \\
\hline
\end{tabular}

Abbreviations: RR, respiratory rate; E/l, expiratory/inspiratory; ns, not significant. 
Table 10 Correlation between cases with/without $\beta 2$ IgM positivity

\begin{tabular}{llllll}
\hline & $\begin{array}{l}\text { Tilt } \\
\text { (RR ratio) }\end{array}$ & $\begin{array}{l}\text { Hand grip } \\
(\mathbf{m m H g})\end{array}$ & $\begin{array}{l}\text { Deep breath } \\
\text { (E/l ratio) }\end{array}$ & $\begin{array}{l}\text { Valsalva } \\
\text { (valsalva ratio) }\end{array}$ & $\begin{array}{l}\text { Lying-to-standing } \\
\text { (mmHg) }\end{array}$ \\
\hline$\beta 2 \operatorname{lgM}+$ & $1.03 \pm 0.14$ & $10.82 \pm 3.93$ & $1.24 \pm 0.11$ & $1.16 \pm 0.18$ & $2.20 \pm 11.23$ \\
$\beta 2 \operatorname{lgM}-$ & $1.12 \pm 0.07$ & $13.60 \pm 5.59$ & $1.37 \pm 0.44$ & $1.37 \pm 0.44$ & $-1.20 \pm 5.54$ \\
$P$ & $\mathrm{~ns}$ & $\mathrm{~ns}$ & $\mathrm{~ns}$ & $\mathrm{~ns}$ & $\mathrm{~ns}$ \\
\hline
\end{tabular}

Abbreviations: RR, respiratory rate; E/l, expiratory/inspiratory; $\beta 2 \mathrm{lgM}$, beta 2-immunoglobulin M glycoprotein antibody test; ns, not significant.

voltage current. The amount of sweat under the capsule was measured repeatedly during the test. Computerized analysis of the results determined how well the sweat gland worked, and how well the nerves functioned to help the gland to release the sweat at a normal rate. (For this test, subjects should not have taken any medication that might interfere with perspiration, such as tricyclic or other antidepressants, selective serotonin reuptake inhibitors, antihistamines, nitropatches, beta-blockers, diuretics, or angiotensin-converting enzyme inhibitors). ${ }^{15}$ Results were presented as mean \pm standard deviation. A probability constant $P<0.05$ was considered significant, and was calculated using Student's $t$-test.

\section{Results}

There were 31 ASP cases (13 male, 18 female; mean age: $47.4 \pm 21$ years), and 31 controls (13 male, 18 female; mean age: $48.9 \pm 25$ years) (Table 2 ). All of the autonomic test results were significantly altered in the ASP cases (Table 3 ). The sweat and Stroop tests were only conducted in seven cases and seven controls. Some cases showed significant alteration, but we did not perform statistical analysis for this small group.

After initial between-group comparisons, a within-group comparison was drawn, to correlate autonomic dysfunction with sex (Table 4), age (Table 5), first manifestation before/ after 30 years of age (Table 6), presence/absence of arterial or venous thrombosis at first manifestation (Table 7), history of disease (more/less than 15 years) (Table 8), antibody positivity (Table 9), and immunoglobulin M or G beta 2-glycoprotein I antibody positivity (Tables 10 and 11). None of these parameters correlated with autonomic dysfunction. However, we found a significant correlation between coagulation parameters and autonomic dysfunction (partial thromboplastin time lupus antibody screening test: PTT-LA) (Figure 1).

\section{Discussion}

Numerous recent works have made it clear that connective tissue diseases correlate with cardiac rhythm disorders, which can be due to endocarditis, myocarditis, or pericarditis, or to coronary thrombotic events or autonomic dysfunction. ${ }^{16,17}$ A recent study showed that autonomic dysfunction is common in autoimmune diseases, ${ }^{18,19}$ and that neuropsychiatric alterations are commonly reported in patients with rheumatic diseases such as SLE, ${ }^{20}$ though researchers were unable to say whether the neural involvement was primary or secondary to the connective disorders. ${ }^{19}$

Our work confirms these autonomic alterations, particularly in APS, in a sizable sample of cases. The numbers of cases considered in other works were very limited, and patients often had other associated diseases, such as SLE. ${ }^{21}$ Our findings seem important because we matched our cases with control subjects, who had no atherosclerotic lesions that might alter the results. Our study also aimed to determine whether autoimmune alterations were the cause of the autonomic disease, or a secondary effect of it.

Our results seem to indicate that thrombophilic states may contribute to neural alterations, probably connected to the cerebrovascular diseases of this syndrome. ${ }^{22}$ If further studies confirm our findings, we might argue that antithrombotic therapy could reduce the possibility of autonomic neural involvement, and thus prevent conduction disorders. This is an indirect, but promising working assumption.

Table I I Correlation between cases with/without $\beta 2 \mathrm{lgG}$ positivity $(>20 \mathrm{U} / \mathrm{mL})$

\begin{tabular}{llllll}
\hline & $\begin{array}{l}\text { Tilt } \\
\text { (RR ratio) }\end{array}$ & $\begin{array}{l}\text { Hand grip } \\
(\mathbf{m m H g})\end{array}$ & $\begin{array}{l}\text { Deep breath } \\
\text { (E/I ratio) }\end{array}$ & $\begin{array}{l}\text { Valsalva } \\
\text { (valsalva ratio) }\end{array}$ & $\begin{array}{l}\text { Lying-to-standing } \\
\text { (mmHg) }\end{array}$ \\
\hline$\beta 2 \operatorname{lgG}+$ & $1.04 \pm 0.13$ & $6.02 \pm 4.03$ & $1.12 \pm 0.11$ & $1.31 \pm 0.19$ & $2.33 \pm 5.27$ \\
$\beta 2 \operatorname{lgG}-$ & $1.12 \pm 0.06$ & $12.33 \pm 5.89$ & $1.38 \pm 0.22$ & $1.41 \pm 0.40$ & $-8.7 \pm 5.13$ \\
$P$ & $\mathrm{~ns}$ & $\mathrm{~ns}$ & $\mathrm{~ns}$ & $\mathrm{~ns}$ & $\mathrm{~ns}$ \\
\hline
\end{tabular}

Abbreviations: RR, respiratory rate; E/l, expiratory/inspiratory; $\beta 2 \operatorname{lgG}$, beta 2-immunoglobulin G glycoprotein antibody test; ns, not significant. 


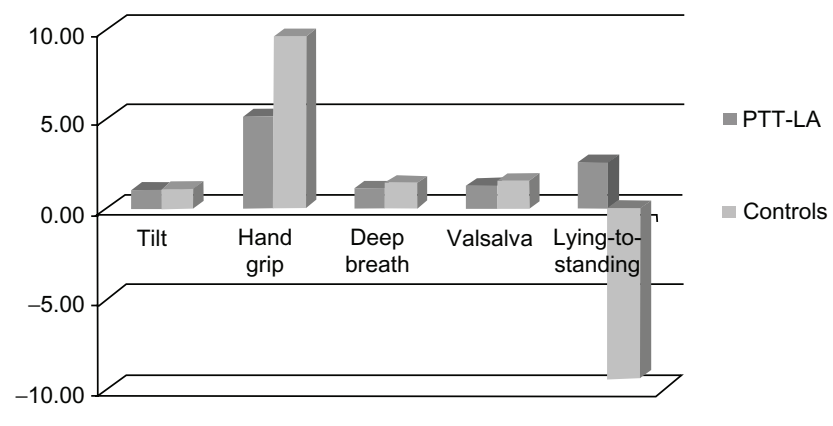

Figure I Correlation between cases with PTT-LA positivity and controls. Notes: Measurement units are: Tilt, RR ratio; Hand grip, mmHg; Deep breath, E/I ratio; Valsalva, Valsalva ratio; Lying-to-standing, $\mathrm{mmHg}$.

Abbreviations: RR, respiratory rate; PTT-LA, partial thromboplastin time lupus antibody screening test.

\section{Conclusions}

Our results show that autonomic dysfunction is associated with primary antiphospholipid syndrome, and correlates closely with thrombophilic states. Further confirmation of this important finding may lead to new therapeutic strategies for treating autonomic dysfunction.

\section{Disclosure}

The authors report no conflicts of interest in this work.

\section{References}

1. Miyakis S, Lockshin MD, Atsumi T, et al. International consensus statement on an update of the classification criteria for definite antiphospholipid syndrome (APS). J Thromb Haemost. 2006;4:295-306.

2. Sanchez-Guerrero J, Alarcon-Segovia D. Primary antiphospholipid syndrome. J Rheumatol. 1989;16:482-488.

3. Gomez-Puerta JA, Martin H, Amigo MC, et al. Long-term follow-up in 128 patients with primary antiphospholipid syndrome: do they develop lupus? Medicine (Baltimore). 2005;84(4):225-230.

4. Asherson RA, Cervera R, de Groot PG, et al; Catastrophic Antiphospholipid Syndrome Registry Project Group. Catastrophic antiphospholipid syndrome: international consensus statement on classification criteria and treatment guidelines. Lupus. 2003;12:530-534.

5. Stramb RH, Baerwald CG, Wahle M, Janig W. Autonomic dysfunction in rheumatic diseases. Rheum Dis Clin North Am. 2005;31(1):61-75, viii.

6. Atojanovich L. Autonomic dysfunction in autoimmune rheumatic disease. Autoimmun Rev. 2009;8(7):569-572.
7. Koszewicz M, Gosk-Bierska I, Bilińska M, et al. Autonomic dysfunction in Raynaud's primary phenomenon. Int Angiol. 2009;28(2):127-131.

8. Gastrineau DA, Kazmier FJ, Nichols WL, Bowie EJM. Lupus anticoagulant: an analysis of the clinical and laboratory features of 219 cases. Am J Heamatol. 1985;19:265-275.

9. Tincani A, Balestrieri G, Spatola L, Cinquini M, Meroli PL, Roubey RA. Anticardiolipin and anti-beta 2 glycoprotein I immunoassay in the diagnosis of antiphospholipid syndrome. Clin Exp Rheumatol. 1998;16(4):396-402.

10. Kuch B, Hense HW, Sinnreich R, et al. Determinants of short-period heart rate variability in the general population. Cardiology. 2001;95 (3): 131-138.

11. Piccirillo C, Fimognari FL, Viola E, Marigliano V. Age-adjusted normal confidence intervals for heart rate variability in healthy subjects during head-up tilt. Int J Cardiol. 1995;50(2):117-124.

12. Gerritsen J, Ten Voorde BJ, Dekker JM, et al. Measures of cardiovascular autonomic nervous function: agreement, reproducibility and reference values in middle age and elderly subjects. J Hypertens Suppl. 1998;16(3):S35-S38.

13. Parry SW, Kenny RA. Tilt table testing in the diagnosis of unexplained syncope. QJM. 1999;92:623-629.

14. Halliwill JR, Lawler LA, EickhoffTJ, Dietz NM, Nauss LA, Joyner MJ. Forearm sympathetic withdrawal and vasodilatation during mental stress in humans. J Physiol. 1997;504 (Pt 1):211-220.

15. Goldberger JJ. Sympathovagal balance: how should we measure it? Am J Physiol. 1999;276:1273-1280.

16. Seferovic PM, Ristic D, Moksimovic R, et al. Cardiac arrhythmias and conduction disturbances in autoimmune rheumatic disease. Rheumatology (Oxford). 2006;45 Suppl 4:39-42.

17. Mattucci-Cerinic M, Seferovic PM. Heart involvement in systemic lupus erythematosus, anti-phospholipid syndrome and neonatal lupus. Rheumatology (Oxford). 2006:45 Suppl 4:8-13.

18. Gundogdu F, unlu Y, Baris N, Arslan S. Antiphospholipid antibody syndrome leading to massive pulmonary embolism and sudden death. Turk Kardiyol Dern Ars; 2008;36(7):467-469.

19. Aydemir M, Yazisiz V, Basaric I, et al. Cardiac autonomic dysfunction in patients with systemic lupus, rheumatoid artrithis and sudden death risk. Lupus. 2010;138(1-2):26-32.

20. Govoni M, Rizzo G, Padovan M, Trotta F. L'interessamento neuropsichiatrico nel lupus eritematoso sistemico: a che punto siamo? [Neuropsychiatric interest in systemic lupus erythematosus: where are we?] Reumatismo. 2005;57(4):215-225. Italian.

21. Shalimar Handa R, Deepak KK, Bhatia K, Aggarwal P, Pandey R. Autonomic dysfunction in systemic lupus erythematosus. Rheumatol Int. 2005;26(9):837-840.

22. Sanna G, Bertolaccini ML, Cuadrado MJ, Khamashta MA, Hughes GR Central nervous involvement in the antiphospholipid (Hughes) syndrome. Rheumatology (Oxford). 2003;42(2):200-213.
International Journal of General Medicine

\section{Publish your work in this journal}

The International Journal of General Medicine is an international, peer-reviewed open-access journal that focuses on general and internal medicine, pathogenesis, epidemiology, diagnosis, monitoring and treatment protocols. The journal is characterized by the rapid reporting of reviews, original research and clinical studies across all disease areas.

\section{Dovepress}

A key focus is the elucidation of disease processes and management protocols resulting in improved outcomes for the patient.The manuscript management system is completely online and includes a very quick and fair peer-review system. Visit http://www.dovepress.com/ testimonials.php to read real quotes from published authors. 